\title{
Automation Systems Design and Laboratory Prototyping Aimed at Mature Petroleum Drilling Rig Retrofitting
}

\author{
Pavle ŠPRLJAN, Danijel PAVKOVIĆ, Mihael CIPEK, Miho KLAIĆ, Tomislav STAROVEŠKI, Davor KOLAR
}

\begin{abstract}
This paper presents a control system design methodology for the drill-string rotary drive and draw-works hoist system aimed at mature drilling rig retrofitting. The rotary drive is equipped with an active damping speed control system featuring a proportional-integral speed controller readily available within modern controlled electrical drives, extended with drill-string back-spinning prevention scheme for the case of stuck tool. The draw-works hoist system features a tool normal force (Weight-on-Bit) controller with tool longitudinal speed (Rate-of-Penetration) limiting functionality. The design of proposed control systems has been based on suitable control-oriented process models and damping optimum criterion which guarantees a desired level of closed-loop system damping. The proposed drilling control systems have been verified on a downscaled laboratory experimental setup, which represents a necessary pre-requirement before these systems are tested in the field.
\end{abstract}

Keywords: active damping; draw-work; laboratory setup; petroleum drilling; proportional-integral controller; retrofitting; top-drive; torsional vibrations

\section{INTRODUCTION}

Diminishing petroleum reserves and related increase in its prices [1] generally stimulate the discovery of new reserves [2], and implementation of advanced drilling technologies [3], especially those aimed at enhanced recovery of hydrocarbons [4]. However, a notable portion of mature petroleum drilling rigs is still equipped with quite functional "legacy" drilling hardware [5], whose useful service life may be prolonged through retrofitting, primarily in terms of control system upgrades [6].

Figure 1 shows the principal schematic representation of one such mature petroleum drilling rig [6]. Borehole drilling is achieved by simultaneous rotary action of the socalled top-drive (based either on the hydraulic or electric motor) and the draw-works hoist electrical drive, wherein the former transfers the torque to the drilling tool via the drill-string, and the latter facilitates drill-string longitudinal motion (Rate-of-Penetration, $R o P$ ) and establishing of drilling tool normal force (Weight-on-Bit, $W o B$ ). Thus, the drilling tool pulverizes the rock material, and the resulting drilling cuttings are removed by drilling fluid (mud) circulated by dedicated mud pumps.

In the case of aforementioned "legacy" drilling systems, the top-drive is typically controlled without regard to the drill-string compliance coupled with the socalled drilling tool stick-slip effect, which cause drill-string system torsional vibrations [7]. These vibrations may, in turn, result in mechanical component wear and fatigue, and decreased borehole drilling rates due to drilling safety concerns (see e.g. [6] and references therein). On the other hand, the draw-works system on such mature drilling rigs is typically manually controlled by means of a mechanical brake [5], which makes these systems' drilling productivity and operational safety less competitive compared to stateof-the-art drilling systems. In order to improve the performance of these mature rigs, they may be retrofitted with advanced drill-string system controls [6]. Moreover, these upgrades are likely to comprise only a fraction of brand new drilling rig cost, which would be affordable to small-to-medium size service companies [8]. To this end, a number of advanced drilling control system concepts have been researched and tested both in the laboratory and in the field, wherein detailed modelling of the drill-string system is key for subsequent control system design [7-17].

An early concept of torsional vibrations suppression system based on passive vibration absorber emulation has been proposed in [7]. Its subsequent development has been directed towards implementation of vibration absorber functionality in servo-controlled rotary electrical drives featuring a standard proportional-integral (PI) speed controller [9]. As shown in [10], PI speed controller tuned for active damping of torsional vibrations may result in notable vibration suppression and increased borehole drilling rates. In order to avoid re-tuning of PI speed controller altogether, the torsional vibrations suppression system in [11] proposes an external drill-string torque feedback, thus including an additional state variable within the control system framework. Even though state control approaches such as those based on $\mathrm{H}_{\infty}$ controller [12] and linear quadratic regulator (LQR) controller [13] can achieve favourable torsional vibration suppression, their implementation requires complete state feedback. For a detailed overview of torsional vibration suppression approaches, the reader is referred to [14].

The retrofitting efforts of draw-works hoist systems have included: (i) servo-pneumatic or servo-hydraulic disk brake system control [15], (ii) electrical servo control of the mechanical brake actuator [16], and (iii) utilization of the main or auxiliary draw-works electric motor [17]. The $W o B$ control can be realized by using a conventional cascade control system structure [15], or more advanced controllers such as the fuzzy logic controller [17], or the passivity-based controller [18]. The latter reference also suggests that additional attenuation of torsional vibrations is possible by means of precise draw-works hoist control.

Having this in mind, the main contribution of this paper is the comprehensive design methodology for the drill-string rotary drive torsional vibration active damping and draw-works hoist-based $W o B$ control systems based on suitable control-oriented process models and damping optimum criterion [19]. In both cases, control systems are based on the well-established PI controllers, with the rotary drilling drive PI speed controller augmented with the backspinning prevention scheme for the case of stuck drilling 
tool. The proposed control systems are verified on a downscaled laboratory experimental setup.

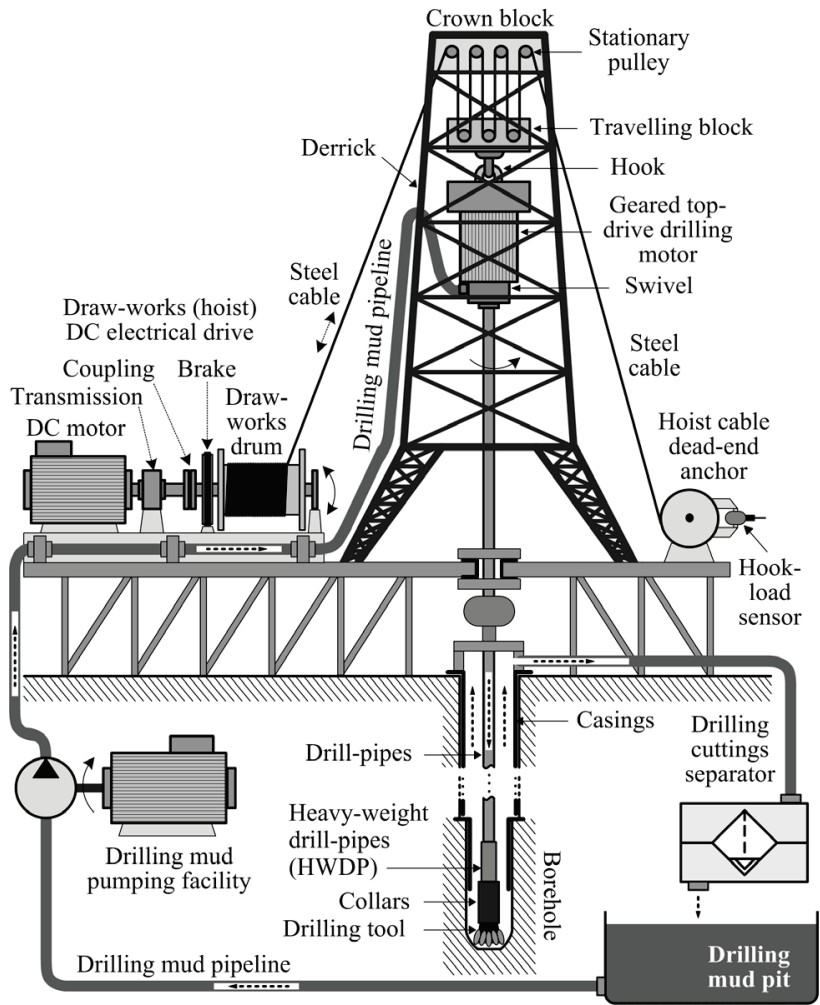

Figure 1 Schematic layout of petroleum drilling rig with top-drive and drawworks drives for drill-string rotary and longitudinal motion

\section{DRILL-STRING SYSTEM MODELLING}

This section presents the drill-string system models for rotational and longitudinal motion along with the accompanying electrical drives and transmission systems.

\subsection{Model for Drill-String Rotational Motion}

The drill-string rotational dynamics are modelled by the so-called two mass elastic system in Fig. 2, wherein drill-pipes act as a torsional spring with their stiffness and damping coefficients $k$ and $c$, respectively [7]. The motor and gearbox inertias are lumped into the motor-side inertia $J_{1}$, while the heavy-weight drill-pipe (HWDP), collar and drill-pipe inertias $\left(J_{h w}, J_{c}\right.$ and $\left.J_{d p}\right)$ and drilling tool inertia $J_{\text {tool }}$ are lumped into the inertia $J_{2}$ at the side of bottom-hole assembly (BHA):

$$
J_{2}=J_{\text {tool }}+J_{c}+J_{h w}+J_{d p}
$$

The model in Fig. 2 is characterized by the following resonance frequencies corresponding to the cases of stuck drilling tool, stiff motor-side speed control, and freelyoscillating drill-string, respectively [4]:

$\Omega_{01}=\sqrt{\frac{k}{J_{1} i^{2}}}, \Omega_{02}=\sqrt{\frac{k}{J_{2}}}, \Omega_{0}=\sqrt{\Omega_{01}^{2}+\Omega_{02}^{2}}$,

The drilling tool-side friction torque $m_{f 2}$ can be described by the generalized Stribeck static curve [20]: $m_{f 2}\left(\omega_{2}\right)=\left[M_{C}+\left(M_{S}-M_{C}\right) e^{-\mid \omega_{2} / \omega_{S} \delta}\right] \operatorname{sgn}\left(\omega_{2}\right)$

where $M_{C}$ is the Coulomb friction torque, $M_{S}$ is the maximum static friction torque, $\delta$ is the so-called Stribeck coefficient and $\omega_{s}$ is the Stribeck speed.

In order to achieve favourable numerical computation efficiency in the zero-speed (stiction) region, the so-called Karnopp friction model modification can be used instead [20]. For the sake of simplicity, a Coulomb model may be used to simulate motor-side friction $\left(m_{f 1}=M_{C m} \operatorname{sgn}\left(\omega_{1}\right)\right)$.

It is assumed that the top-drive electrical motor is equipped with an appropriate power converter unit with embedded fast current/torque control loop, characterized by a rather small overall torque lag $T_{\Sigma}$ with respect to torque reference $m_{1 R}$ within the closed-loop model [21]:

$m_{1}(s)=\frac{1}{T_{\Sigma} s+1} m_{1 R}(s)$

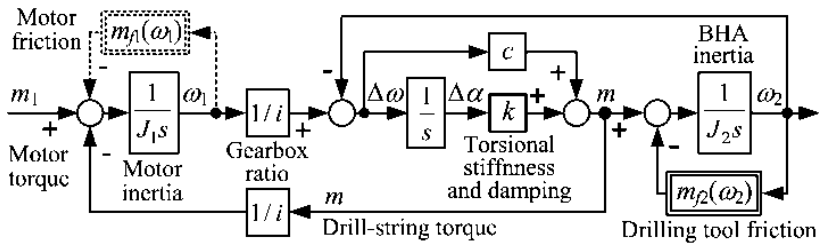

Figure 2 Block-diagram of drill-string system model for rotational motion

\subsection{Model for Drill-String Longitudinal Motion}

The drill-string model for longitudinal motion is depicted by the block diagram in Fig. 3, which comprises several sub-models. It is assumed herein that the drawworks electrical drive is driven by a power converter unit with embedded torque and speed controllers, tuned to achieve fast and well-damped speed control loop response. In that case, the load effect due to steel-rope force tension can be effectively dealt with the fast speed controller [21], and the draw-works motor speed $\omega_{w}$ vs. speed target $\omega_{R w}$ response dynamics can be approximated by a first order lag term:

$\omega_{w}(s)=\frac{1}{T_{e \omega} s+1} \omega_{R w}(s)$

The resulting draw-works drive speed $\omega_{w}$ is translated to the steel rope tangential speed $v_{r}$ at the drum through the ratio of drum radius $r_{d}$ and motor gearbox ratio $i_{g}$. The steel rope speed $v_{r}$ represents the input of the steelrope and travelling block mass-spring subsystem, characterized by its mass $m_{h}$ and steel rope stiffness and damping coefficients $k_{r}$ and $c_{r}$, respectively. The hook mass is accelerated by the sum of forces acting upon it, which include the rope force $F_{r}$ transmitted through the pulley system with transmission ratio $z$, the gravity-related hookload $m_{h} g\left(g=9.81 \mathrm{~m} / \mathrm{s}^{2}\right)$ and the dilatation force $F_{d s}$ of the drill-string.

The travelling block longitudinal speed $v_{h}$ is fed to the drill-string vs. BHA mass-spring subsystem [15], characterized by its stiffness and damping coefficients $k_{d s}$ and $c_{d s}$, and total mass $m_{B}$ at the BHA side, which is subject 
to the combined action of its gravity $m_{B} g$, drill-string buoyancy $F_{b}$ and drilling tool force characterized by its penetration resistance $c_{t}$.

The $W o B$ measurement model is based on quasi-static hook-load measurement $\left(z F_{r}\right)$ via hook-load sensor mounted at the steel rope dead-end anchor point (see Fig. 1). The hook-load is corrected by the drill-string free hanging force offset $F_{\text {off }}$ (no drilling tool vs. borehole contact) in order to obtain the actual drilling tool normal force. This force measurement signal in Newtons is scaled to tons through the scaling factor $K_{f}$, and also low-pass filtered, with the filter characterized by its equivalent time constant $T_{f}$.

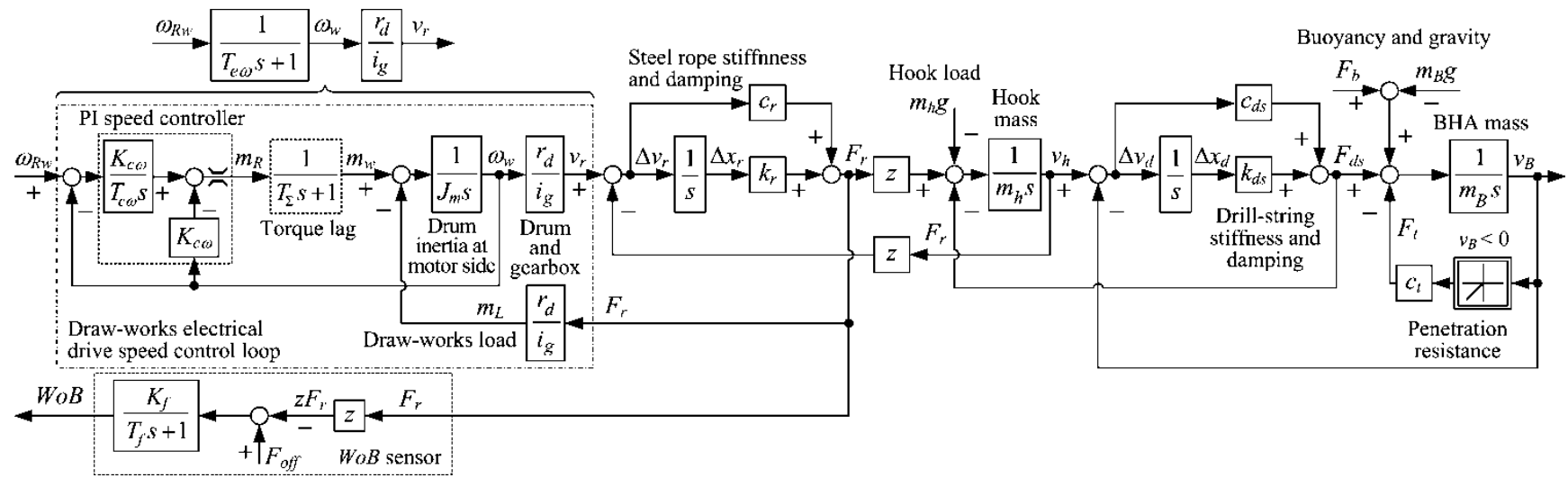

Figure 3 Block-diagram of drill-string dynamic model for longitudinal motion with WoB measurement and draw-works electrical drive models

A linear process model for drill-string longitudinal motion under the assumption of negligible drill-string and steel rope damping $\left(c_{d s} \approx 0\right.$ and $\left.c_{r} \approx 0\right)$ and established drilling tool penetration $\left(v_{B}<0\right.$ in Fig. 3) can be represented by the following transfer function $\Delta W o B(s) / \Delta \omega_{R}(s)$ relating the Weight-on-Bit measurement change to draw-works drive speed reference variations:

$$
G_{w}(s)=\frac{-K_{p w}\left(b_{3} s^{3}+b_{2} s^{2}+b_{1} s+1\right)}{\left(a_{4} s^{4}+a_{3} s^{3}+a_{2} s^{2}+a_{1} s+1\right)\left(T_{e \omega} s+1\right)\left(T_{f} s+1\right)}
$$

with the transfer function coefficients $b_{1}, \ldots, b_{3}$ and $a_{1}, \ldots$, $a_{4}$ listed in Tab. 1, and the model gain $K_{p w}$ defined as:

$$
K_{p w}=\frac{K_{f} c_{t} r_{b}}{i_{g} z}
$$

Table 1 Denominator and numerator coefficients of drill-string transfer function model for longitudinal motion

\begin{tabular}{|c|c|}
\hline$a_{1}=\frac{c_{t}\left(z^{2} k_{r}+k_{d s}\right)}{z^{2} k_{d s} k_{r}}$ & $b_{1}=\frac{m_{h}+m_{B}}{c_{t}}$ \\
\hline$a_{2}=\frac{m_{B}}{k_{d s}}+\frac{m_{h}+m_{B}}{z^{2} k_{r}}$ & $b_{2}=\frac{m_{h}}{k_{d s}}$ \\
\hline$a_{3}=\frac{m_{h} c_{t}}{z^{2} k_{d s} k_{r}}$ & $b_{3}=\frac{m_{h} m_{B}}{k_{d s} c_{t}}$ \\
\hline$a_{4}=\frac{m_{h} m_{B}}{z^{2} k_{d s} k_{r}}$ & \\
\hline
\end{tabular}

The above model, being characterized by two masses and two compliance elements is likely to feature distinct resonance modes. Fig. 4 shows the frequency characteristics (Bodé plots) of the above drill-string model (for actual model parameters used in the analysis, please refer to Section 4). Fig. 4 also shows the comparative Bodé plots of the simplified first-order lag model characterized by equivalent model gain $K_{p w}$ and time constant $T_{p w}$, which approximates the $W o B v s$. speed reference $\omega_{R}$ behaviour in the low-frequency range:

$G_{w}(s)=\frac{-K_{p w}}{T_{p w} s+1}=\frac{-K_{p w}}{\left(T_{e \omega}+T_{f}+a_{1}\right) s+1}$

where the negative sign of process model gain relates to the -180 degree phase lag of the frequency characteristic, or more precisely, the negative sign of steel rope tension force $z F_{r}$ in $W o B$ measurement model in Fig. 3.

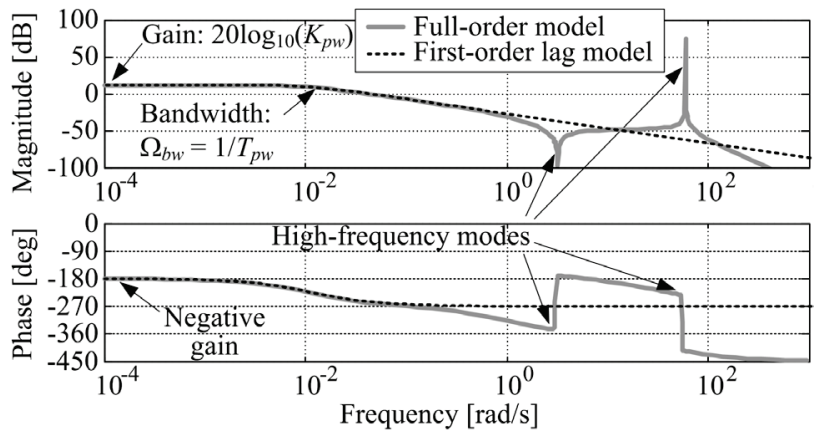

Figure $4 W_{O} B$ vs. $\omega_{R}$ frequency characteristics

In the mid-to high frequency range, there is a clear discrepancy between the approximate model (8) and the full-order model due to steel rope and drill-pipe resonance frequencies. Nevertheless, the dominant low-frequency process dynamics should be rather slow (i.e. characterized by a narrow bandwidth $\Omega_{b w}$ ), and the approximate model (8) may be used in the $W o B$ control system design [22].

\section{CONTROL SYSTEM DESIGN}

This section presents the control system design based on damping optimum criterion for rotary drive torsional vibrations active damping equipped with safe drill-string 
unwinding in case of stuck drilling tool, and draw-works drive-based Weight-on-Bit control.

\subsection{Damping Optimum Criterion}

The controller tuning herein is based on the damping optimum (or double ratios) criterion [19], which is a poleplacement-like method of design of linear continuous-time closed-loop systems with a full-order or reduced-order controller. The controller tuning procedure is based on the following formulation of the closed-loop characteristic polynomial:

$$
A(s)=D_{2}^{n-1} D_{3}^{n-2} \cdots D_{n} T_{e}^{n} s^{n}+\cdots+D_{2} T_{e}^{2} s^{2}+T_{e} s+1
$$

where $T_{e}$ is the closed-loop system equivalent time constant, and $D_{2}, D_{3}, \ldots, D_{n}$ are the so-called characteristic ratios, and $n$ is the closed-loop system order.

When all characteristic ratios are set to optimal values $D_{2}=D_{3}=, \ldots$, $=D_{n}=0.5$ (by means of a full-order controller), the closed-loop system has a quasi-aperiodic step response with an overshoot of approximately $6 \%$ and the approximate settling time of 1.8-2.1 $T_{e}$. If a reducedorder controller of order $r$ is used, only the dominant characteristic ratios $D_{2}, \ldots, D_{r+1}$ are set to desired values.

The closed-loop damping is primarily determined by the value of the most dominant characteristic ratio $D_{2}$. By decreasing its value (i.e. for $D_{2} \leq 0.35$ ) the closed-loop system is characterized by aperiodic step reference response without overshoot. Moreover, by increasing the $T_{e}$ value, the control system robustness and noise sensitivity are generally improved, with the consequence of slower response and less efficient disturbance rejection.

\subsection{Torsional Vibrations Active Damping System}

Fig. 5a shows the block diagram representation of the cascade control system for drill-string electrical drive speed control, wherein the superimposed PI speed controller commands the torque reference $m_{1 R}$ to the inner torque control system within the power converter. Assuming that the overall torque lag $T_{\Sigma}$ is small $\left(T_{\Sigma}<<\Omega_{02}\right)$ [10], the drilling tool is freely rotating $\left(\left|\omega_{2}\right|>0, m_{f 2}=0\right)$, and the drill-string damping coefficient is negligible $(c=$ 0 ), the following fourth-order transfer function model is obtained between the speed reference $\omega_{R}$ and tool speed $\omega_{2}$ referred to the motor side (cf. Figs. 2 and 5a):

$$
G_{c}(s)=\frac{i \omega_{2}(s)}{\omega_{R}(s)}=\frac{1}{a_{c 4} s^{4}+a_{c 3} s^{3}+a_{c 2} s^{2}+a_{c 1} s+1}
$$

with the transfer function coefficients defined as:

$$
\begin{aligned}
& a_{c 4}=\left(J_{1}+J_{2} / i^{2}\right) T_{c \omega} K_{c \omega}^{-1} \Omega_{0}^{-2} \\
& a_{c 3}=T_{c \omega} \Omega_{02}^{-2} \\
& a_{c 2}=\left(J_{1}+J_{2} / i^{2}\right) T_{c \omega} K_{c \omega}^{-1}+\Omega_{02}^{-2} \\
& a_{c 1}=T_{c \omega}
\end{aligned}
$$

In order to obtain the analytical expressions for the PI controller integral time constant $T_{c \omega}$ and proportional gain $K_{c \omega}$, the transfer function (10) denominator coefficients $a_{c 1}$, $a_{c 2}, a_{c 3}$ and $a_{c 4}$ are equated with the coefficients of the fourth-order damping optimum characteristic polynomial according to (9). The final result reads as follows:

$$
\begin{aligned}
& T_{c \omega}=T_{e}=\frac{1}{D_{2 \omega} \sqrt{D_{3 \omega}} \Omega_{02}} \\
& K_{c \omega}=\frac{T_{c \omega}\left(J_{1}+J_{2} / i^{2}\right) \Omega_{02}^{2}}{D_{2 \omega} T_{c \omega}^{2} \Omega_{02}^{2}-1}
\end{aligned}
$$

thus indicating that the PI speed controller is tuned with respect to the drilling tool-side resonance frequency $\Omega_{02}$, and the closed-loop system dominant dynamics should be well-damped for the optimal characteristic ratio values $\left(D_{2 \omega}=D_{3 \omega}=0.5\right)$. Note, however, that the PI controller has only two parameters $\left(K_{c \omega}\right.$ and $\left.T_{c} \omega\right)$, and is thus unable to optimally tune the damping of high-frequency modes related to the non-dominant characteristic ratio $D_{4 \omega}[10]$.

In contrast to the above tuning approach the more commonly-used symmetrical optimum tuning criterion [21] only accounts for the overall inertia and torque lag:

$T_{c \omega}=4 T_{\Sigma}$
$K_{c \omega}=\frac{J_{1}+J_{2} / i^{2}}{2 T_{\Sigma}}$

which results in "stiff" control of motor speed, but does not account for drill-string compliance effects [10].

The torsional vibration active damping system based on PI speed controller is extended with the prevention of the so-called back-spinning effect [10], which is based on simple flip-flop logic, and superimposed to the speed control system as shown in Fig. 5b. Namely, detection of stuck drilling tool condition is indicated if notable error of model-based rotary drive speed prediction $\omega_{m}$ occurs simultaneously with large torque command $m_{1 R}$ to the topdrive motor. In that case, the flip-flop is set, and a small negative speed reference is commanded to unwind the drill-string in a controllable way. The speed reference $\omega_{R}$ is returned to the operator's reference $\omega_{R, o p}$ (the flip-flop is reset) when the drill-string is sufficiently unwound.

An additional torque reserve should be added to the operator's torque limit $M_{m, o p}$ during constrained motion to enable safe unwinding of the rotary drilling drive [10]:

$$
M_{\text {res }}=J_{1} \omega_{1 s} \Omega_{01}
$$

which accounts for the accumulated motor momentum under constrained motion conditions $J_{1} \omega_{1 s}$ and the natural frequency of drilling motor vibrations $\Omega_{01}$ under stuck drilling tool conditions (see [10]). The steady-state topdrive speed $\omega_{1 s}$ under constrained motion conditions can be estimated from the commanded speed target $\omega_{R, o p}$ by using the following straightforward relationship [10]:

$\omega_{1 s}=\left(1+J_{1} \Omega_{01}^{2} T_{c \omega} / K_{c \omega}\right)^{-1} \omega_{R, o p}$ 

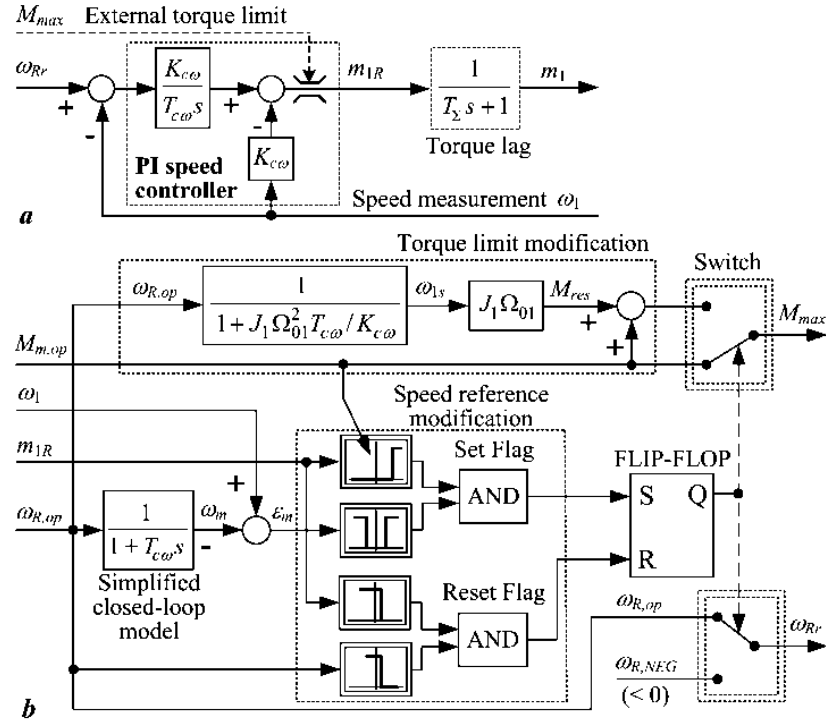

Figure 5 Block diagram of active damping control strategy featuring PI speed controller (a) and back-spinning prevention algorithm (b)

\subsection{Weight-on-Bit Control System}

Fig. 6 shows the block diagram of the $W o B$ PI controller, which supplies the speed reference $\omega_{R}$ to the lower-level draw-works electrical drive speed control loop ( $W o B$ controller is cascaded to the draw-works inner speed control loop). The speed reference $\omega_{R}$ provided by the $W o B$ controller is limited for the downward motion of the drillstring to the maximum safe value $\omega_{\max }$ predefined by the operator. The controller output sign reversal is due to $W o B$ sensor model in Fig. 3.

The controller design is based on the simplified control-oriented process model (8), which results in the following $W o B$ control system closed-loop model:

$$
G_{c}(s)=\frac{K_{w o b} K_{p w}}{T_{p w} T_{w o b} s^{2}+\left(1+K_{w o b} K_{p w}\right) T_{w o b} s+K_{w o b} K_{p w}}
$$

Again, by applying the damping optimum tuning procedure (with $n=2$ in equation (9)), the following analytical expressions are obtained for the PI controller gain and integral time constant, respectively:

$$
\begin{aligned}
& K_{w o b}=\frac{1}{K_{p w}}\left(\frac{T_{p w}}{D_{2 w} T_{e w o b}}-1\right) \\
& T_{w o b}=T_{e w o b}\left(1-\frac{D_{2 w} T_{e w o b}}{T_{p w}}\right) \\
& 0<T_{\text {ewob }}<\frac{T_{p w}}{D_{2 w}}
\end{aligned}
$$

wherein the inequality condition (24) relates to the feasibility of equivalent closed-loop time constant $T_{\text {ewob }}$ in terms of obtaining non-negative controller parameters.

Note that a smaller value of the equivalent time constant $T_{\text {ewob }}$ may result in increased sensitivity of the closed-loop system high-frequency modes to model approximation error (cf. Eqs. (6) and (8)). Hence, a larger
$T_{\text {ewob }}$ choice should be preferred in order to obtain robust closed-loop behaviour in the high-frequency range. Moreover, in order to avoid the $W o B$ response overshoot beyond the target value, the characteristic ratio $D_{2 w}$ should also be decreased below the optimal value.

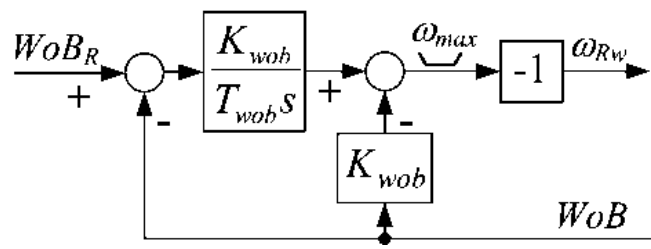

Figure 6 Block diagram of Weight-on-Bit PI controller

\section{EXPERIMENTAL RESULTS}

The proposed drilling control systems have been verified experimentally on a downscaled drill-string system laboratory setup developed in [22], whose principal schematic is shown in Fig. 7. It comprises a dual electrical drive with identical torque and speed ratings $\left(M_{r}=3.78 \mathrm{Nm}\right.$ and $\left.\omega_{r}=1390 \mathrm{rpm}\right)$. One of the servo-controlled induction motors (IMs) is used as the controlled electrical drive, while the second motor is used to emulate a realistic load from the working mechanism. The load "emulator" drive receives a suitable torque reference from the industrial PC, which runs the real-time simulation of rotary or drawworks drive dynamics, and also performs on-line data logging. An additional inertia disk with inertia $J_{r}=0.0122$ $\mathrm{kgm}^{2}$ is inserted between the motors in order to achieve similar starting dynamics of the downscaled drive and the actual drive in the field. Tabs. 2 and 3 list the parameters of the realistic drill-string system, downscaled to the lowpower laboratory setup based on the methodology presented in [10]. For the sake of simplicity, the recorded variables (with the exception of $W o B$ ) are presented in per unit (p.u.) system, with the normalization of variables based on actual top-drive speed and torque ratings and gearbox ratios in Tabs. 2 and 3.

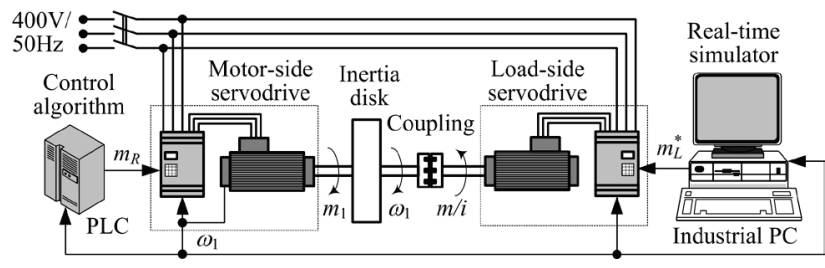

Figure 7 Principal schematic of down-scaled laboratory experimental setup

Table 2 Parameters of realistic drill-string system for rotational motion

\begin{tabular}{|l|l|}
\hline \multicolumn{1}{|c|}{ Parameter } & \multicolumn{1}{c|}{ Value } \\
\hline Rated top-drive motor torque $M_{n}$ & $3200 \mathrm{Nm}$ \\
\hline Rated top-drive motor speed $\omega_{n}$ & $187.5 \mathrm{rad} / \mathrm{s}$ \\
\hline Overall motor torque lag $T_{\Sigma}$ & $4 \mathrm{~ms}$ \\
\hline Gearbox ratio $i$ & 12.5 \\
\hline Top-drive motor-side inertia $J_{1}$ & $10 \mathrm{kgm}^{2}$ \\
\hline BHA-sideinertia $J_{2}$ & $301.1 \mathrm{kgm}$ \\
\hline Drill-string stiffness coefficient $k$ & $618.3 \mathrm{Nm} / \mathrm{rad}$ \\
\hline Drill-string damping coefficient $c$ & $15.3 \mathrm{Nms} / \mathrm{rad}$ \\
\hline Drilling tool-side static friction torque $M_{S}$ & $4000 \mathrm{Nm}$ \\
\hline Drilling tool-side Coulomb torque $M_{C}$ & $2500 \mathrm{Nm}$ \\
\hline Stribeck speed $\omega_{s}$ & $0.1 \mathrm{rad} / \mathrm{s}$ \\
\hline Stribeck coefficient $\delta_{s}$ & 1.0 \\
\hline
\end{tabular}


Table 3 Parameters of realistic drill-string system for longitudinal motion

\begin{tabular}{|l|l|}
\hline \multicolumn{1}{|c|}{ Parameter } & \multicolumn{1}{c|}{ Value } \\
\hline Rated draw-works motor torque $M_{n}$ & $7920 \mathrm{Nm}$ \\
\hline Rated draw-works motor speed $\omega_{n}$ & $101.5 \mathrm{rad} / \mathrm{s}$ \\
\hline Draw-works drum inertia at motor side $J_{m}$ & $42 \mathrm{kgm}^{2}$ \\
\hline Motor speed control loop lag $T_{e}$ & $16 \mathrm{~ms}$ \\
\hline Gearbox ratio $i_{g}$ & 12.5 \\
\hline Drum radius $r_{d}$ & $0.381 \mathrm{~m}$ \\
\hline Travelling block mass $m_{\text {hook }}$ & $11013 \mathrm{~kg}$ \\
\hline Total mass at BHA side $m_{t o t}$ & $74138 \mathrm{~kg}$ \\
\hline Steel rope stiffness coefficient $k_{r}$ & $2.16 \cdot 10^{6} \mathrm{~N} / \mathrm{m}$ \\
\hline Steel rope damping coefficient $c_{r}$ & $100 \mathrm{Ns} / \mathrm{m}$ \\
\hline Drill-string stiffness coefficient $k_{d s}$ & $1.14 \times 10^{5} \mathrm{~N} / \mathrm{m}$ \\
\hline Drill-string damping coefficient $c_{d s}$ & $100 \mathrm{Ns} / \mathrm{m}$ \\
\hline$W o B$ measurement model gain $K_{f}$ & $1 / 9810 \mathrm{t} / \mathrm{N}$ \\
\hline$W o B$ measurement model time constant $T_{f}$ & $1 \mathrm{~s}$ \\
\hline
\end{tabular}

Fig. 8 shows the experimental results for the case of drill-string rotary speed control system. The benchmark results for the case of fast PI speed controller tuned according to Eqs. (17) and (18), and subject to drill-string compliance and variable drilling tool friction torque are shown in Fig. 8a. The fast PI controller is capable of maintaining the motor speed in the close vicinity of the target value regardless of the load caused by the drill-string compliance and drilling tool stick-slip friction resulting in notable limit-cycle oscillations of the drilling tool speed $\omega_{2}$ and drill-string torque $m$ (see Subsection 3.3). The relatively large bias between the motor torque and the drillstring torque is caused by the friction within the laboratory system transmission mechanism, with the Coulomb torque estimated to $M_{C m}=0.16$ per units. The aforementioned undesirable torsional vibrations are effectively damped by means of active damping PI speed controller tuned according to Eqs. (15) and (16), as illustrated in Fig. 8b. This consequently leads to rather favourable damping of both the motor-side and drilling tool-side vibration modes, and results in effective suppression of stick-slip motion effect. Fig. 8c shows the responses of the drill string speed control system in the case of stuck drilling tool with the back-spinning intervention turned on. The proposed backspinning prevention scheme enables safe unwinding of the drill-string by internally applying a negative speed reference until a rather small (safe) torque value is reached. Once unwound, the rotary drilling drive may be commanded by a zero speed reference in order to keep it at standstill.

Fig. 9 shows the $W o B$ control system responses for different operating conditions. Figure 9a shows the $W o B$ reference step responses $\left(W o B_{R}=8 \mathrm{t}\right)$ for the case of drilling tool penetration resistance coefficient $c_{t}=10^{7}$ $\mathrm{Ns} / \mathrm{m}$ and $W o B$ PI controller tuned for step response without overshoot $\left(T_{\text {ewob }}=36 \mathrm{~s}\right.$ and $\left.D_{2 w}=0.25\right)$. The drawworks drive rotational speed $\omega_{w}$ is characterized by a notable initial drop, which is requested by the superimposed $W o B$ controller in order to develop the requested $W o B$. This, in turn, compresses the drill-string in the longitudinal direction during the $W o B$ transient phase, which is characterized by zero overshoot. Once the steadystate $W o B$ value of $8 \mathrm{t}$ is achieved, constant drilling tool penetration rate (draw-works drive speed $\omega_{w}$ ) is maintained by the draw-works drive under the steady-state command from the $W o B$ controller. In the case when the drilling tool encounters a rock formation characterized by different penetration resistance (Figs. 9b and 9c), WoB controller adjusts the draw-works drive speed $\omega_{w}$ in order to achieve the desired $W o B$ value. In the case of drilling tool penetration resistance decrease from $c_{t}=10^{7} \mathrm{Ns} / \mathrm{m}$ to $c_{t}=$ $3 \times 10^{6} \mathrm{Nm} / \mathrm{s}$ (Fig. 9b), the $W o B$ controller output becomes saturated, because the drive speed reference is limited to $\omega_{\max }=4 \mathrm{rad} / \mathrm{s}$ in order to avoid possibly hazardous fast unwinding of the steel rope from the drum. Hence, the $W o B$ control system is characterized by steady-state $W o B$ control error of approximately $1.5 \mathrm{t}$ in this scenario. Figure $9 \mathrm{c}$ shows that when encountering a "harder" rock formation ( $c_{t}$ increases from $10^{7} \mathrm{Ns} / \mathrm{m}$ to $2 \times 10^{7} \mathrm{Nm} / \mathrm{s}$ ), the controller needs to effectively decrease the drive speed $\omega_{w}$. In particular, the controller quite effectively suppresses the resulting $W o B$ excursion due to increased penetration resistance, i.e. only $6 \%$ overshoot occurs with respect to the $W o B$ target value.
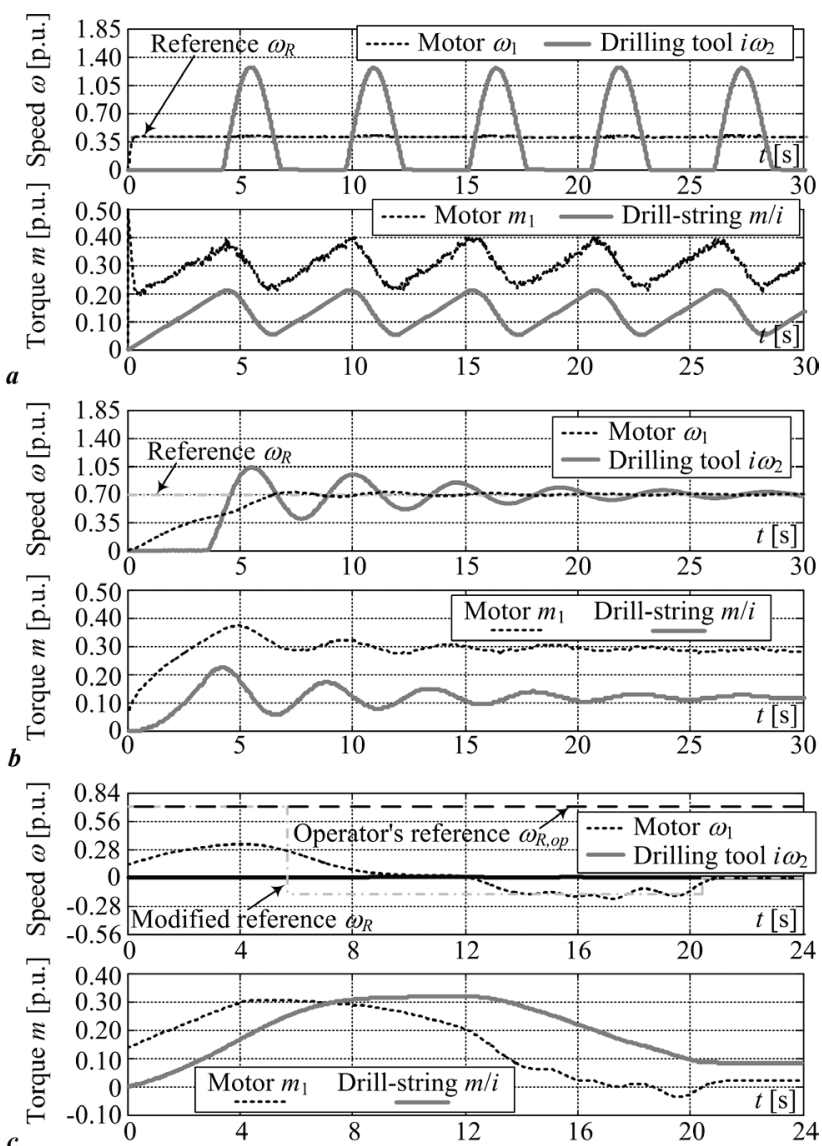

Figure 8 Experimental responses of drill-string speed control system without active damping (a), with active damping (b), and for stuck tool case with backspinning prevention turned on (c)

\section{CONCLUSION}

The paper has presented the results of petroleum drilling drill-string modelling and control system design for rotary and longitudinal motion aimed at mature petroleum drilling rig retrofitting. In particular, the rotary drive active damping speed control system and the drawworks hoist-based Weight-on-Bit $(W o B)$ control system have been based on proportional-integral controllers. The controller tuning has been based on the simplified linear control-oriented process models and damping optimum criterion, resulting in straightforward expressions between 
controller parameters, process model parameters and damping tuning parameters (i.e. characteristic ratios).

The presented drilling control systems have been verified on a downscaled laboratory experimental setup. The active damping rotary speed control system has been able to effectively suppress the torsional vibrations due to drilling tool stick-slip effect. Moreover, the proposed backspinning prevention scheme accurately detects the stuck drilling tool condition and safely unwinds the drill-string under the proposed speed control scheme. The proposed $W o B$ control system has been able to achieve well-damped closed-loop $W o B$ response under different drilling conditions. This is particularly emphasized in the case of the drilling tool suddenly encountering "softer" or "harder" rock formations. In the former case, the target penetration rate has been limited in order to avoid potentially hazardous fast unwinding of the steel rope from the drawworks drum, while in the latter case the penetration rate has been decreased in order to quickly suppress the $W o B$ excursion from the target value.

The main advantages of the proposed control system design methodology are: (i) utilization of modular cascade control system structure, (ii) realization by means of wellestablished proportional-integral (PI) control laws for both control tasks, and (iii) simplicity of the controller design based on suitably-chosen control-oriented process models and damping optimum criterion. These features are in fact desirable, because they do not require significant modifications of the existing control platforms.

Future work is going to be directed towards detailed testing of the proposed control systems in the field. Additional research efforts may also include different aspects of drilling process modelling and control related to directional drilling and well-bore interaction.
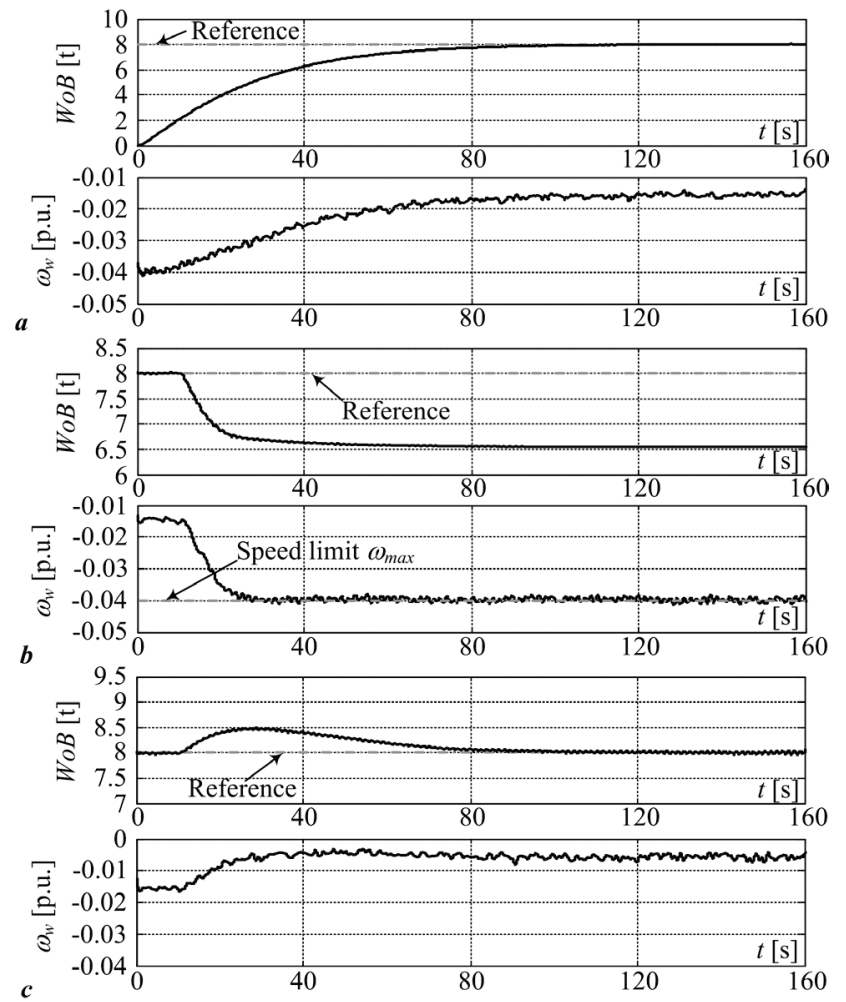

Figure 9 Experimental responses of drill-string WoB control system for constant penetration resistance (a), penetration resistance decrease (b), and penetration resistance increase (c)

\section{Acknowledgements}

This research has been supported by HAMAG-BICRO through the grant "Advanced Systems for Drilling Control at Hydrocarbon Exploration Facilities" (IR-2015-48), and by the European Regional Development Fund under the grant KK.01.1.1.01.0009 (DATACROSS).

\section{Nomenclature}

$\begin{array}{ll}\text { Abbreviations } \\ \text { BHA } & \text { Bottom-hole assembly } \\ \text { HWDP } & \text { Heavy-weight drill-pipes } \\ \text { H}_{\infty} & \text { H-infinity robust controller design } \\ \text { IM } & \text { Induction machine } \\ \text { LQR } & \text { Linear quadratic regulator } \\ \text { PI } & \text { Proportional-integral (controller) } \\ \text { RoP } & \text { Rate-of-Penetration }\end{array}$

Variables

$F_{b}, F_{t} \quad$ Buoyancy and tool penetration force

$F_{r}, F_{d s} \quad$ Steel rope force and drill-string dilatation force

$m_{1}, m \quad$ Rotary drive motor torque, drill-string torque

$m_{f 1}, m_{f 2} \quad$ Rotary drive motor and BHAside friction torque

$M_{m, o p} \quad$ Operator's torque limit for rotary drive

$M_{\max } \quad$ Modified torque limit for rotary drive

$v_{B}, v_{r} \quad$ BHA and steel rope longitudinal speed, respectively

$W o B \quad$ Weight-on-Bit (measurement)

$W o B_{R} \quad W o B$ reference (target) value

$\Delta v_{r}, \Delta x_{r} \quad$ Steel rope dilatation speed and dilatation

$\Delta v_{d}, \Delta x_{d} \quad$ Drill-string dilatation speed and dilatation

$\Delta \omega, \Delta \alpha \quad$ Rotary speed difference and torsional angle

$\omega_{R, o p} \quad$ Operator's speed target for rotary drive

$\omega_{R r} \quad$ Modified speed target for rotary drive

$\omega_{w}, \omega_{R w} \quad$ Draw-works drive speed and reference value

$\omega_{1}, \omega_{2} \quad$ Rotary drive motor speed and BHA-side speed

$\omega_{1 s} \quad$ Constrained motionrotary drive speed

\section{Parameters}

$c_{t} \quad$ Tool penetration resistance coefficient

$D_{2}, \ldots, D_{n}$ Damping optimum characteristic ratios

$g \quad$ Gravity (free-fall) acceleration

$i, i_{g}, \quad$ Rotary anddraw-works drive transmission ratios

$J_{1}, J_{2} \quad$ Rotary drive motor-side and BHA-side inertia

$J_{\text {tool}}, J_{c} \quad$ Tool and collar inertia

$J_{h w}, J_{d p} \quad$ HWDP and drill-pipe inertia

$k, c \quad$ Drill-string torsional stiffness and damping

$k_{r}, c_{r} \quad$ Steel rope longitudinal stiffness and damping

$k_{d s}, c_{d s} \quad$ Drill-string longitudinal stiffness and damping

$K_{c \omega}, T_{c \omega} \quad$ Rotary drive PI controller gain and time constant

$K_{w o b}, T_{w o b} W o B$ PI controller gain and time constant

$K_{p w}, T_{p w} \quad$ Simplified model equivalent gain and time constant

$m_{h}, m_{B} \quad$ Hook mass and BHA mass

$M_{C}, M_{S} \quad$ Rotary drive BHA-side Coulomb and static friction

$M_{C m} \quad$ Rotary drive motor-side Coulomb friction

$r_{d} \quad$ Draw-works drum radius

$T_{e} \quad$ Damping optimum equivalent time constant

$T_{\text {ewob }} \quad W o B$ control system equivalent time constant

$T_{f} \quad W o B$ measurement time constant

$T_{\Sigma} \quad$ Rotary drive torque lag

$T_{e \omega} \quad$ Draw-works drive speed control loop lag

$z \quad$ Pulley transmission ratio

$\delta, \omega_{s} \quad$ Stribeck coefficient and Striebeck speed

$\Delta_{\omega} \quad$ Zero-speed region (Karnopp friction model)

$\Omega_{0} \quad$ Freely-oscillating resonance frequency

$\Omega_{01} \quad$ Motor-side resonance frequency

$\Omega_{02} \quad$ Tool-side resonance frequency

$\Omega_{b w} \quad$ Bandwidth of longitudinal dynamics model 


\section{REFERENCES}

[1] Bardi, U. (2009). Peak Oil: The four stages of a new idea. Energy, 34(3), 323-326. https://doi.org/10.1016/j.energy.2008.08.015

[2] Sorrell, S., Speirs, J., Bentley, R., Brandt, A., \& Miller, R. (2006). Global oil depletion: A review of the evidence. Energy Policy, 38(9), 5290-5295. https://doi.org/10.1016/j.enpol.2010.04.046

[3] Luo D. \& Zhao, X. (2012). Modeling the operating costs for petroleum exploration and development projects. Energy 40(1), 189-195. https://doi.org/10.1016/j.energy.2012.02.006

[4] Ma, T.-H., Wu, Q.-A., Tang, C.-A., \& Liu, H.-Y. (2016). Hydraulic Fracturing Propagation Mechanism during Shale Gas Reservoir Stimulation through Horizontal Well. Tehnički vjesnik - Technical Gazette, 23(2), 477-490. https://doi.org/10.17559/TV-20151216024823

[5] Lyons, W. C. \& Plisga G. J. (2005). Standard Handbook of Petroleum \& Natural Gas Engineering, Burlington: Gulf Professional Publishing.

[6] Pavković, D. (2017). Current Trends in Oil Drilling Systems R\&D with Emphasis on Croatian Oil Drilling Sector - A Review. Proceedings of $9^{\text {th }}$ International Conference on Management of Technology - Step to Sustainable Production, Dubrovnik, Croatia, 1-20.

[7] Jansen, J.D. \& van den Steen, L. (1995). Active Damping of Self-Excited Torsional Vibrations in Oil Well Drill-strings. Journal of Sound and Vibration, 179(4), 647-668. https://doi.org/10.1006/jsvi.1995.0042

[8] Kaiser, M. J. \& Snyder, B. F. (2013). The Offshore Drilling Industry and Rig Construction in the Gulf of Mexico, London: Springer-Verlag.

[9] Runia, D. J., Grauwmans, R., \& Stulemeijer, I. (2013). A Brief History of the Shell "Soft Torque Rotary System" and Some Recent Case Studies. Proceedings of SPE/IADC Drilling Conference (SPE paper No. 163548), Amsterdam, Netherlands. https://doi.org/10.2118/163548-MS

[10] Pavković, D., Deur, J., \& Lisac, A. (2011). A Torque Estimator-based Control Strategy for Oil-Well Drill-string Torsional Vibrations Active Damping Including an Autotuning Algorithm. Control Engineering Practice, 19(8) 836850. https://doi.org/10.1016/j.conengprac.2011.04.012

[11] Dwars, S. (2014). Recent Advances in Soft Torque Rotary Systems. Proceedings of $3^{\text {rd }}$ International Colloquium on Nonlinear Dynamics and Control of Deep Drilling Systems, Minneapolis, USA, 29-44.

[12] Serrarens, A. F. A., Van de Molengraft, M. J. G., Kok, J. J., \& van den Steen, L. (1998). $\mathrm{H}_{\infty}$ Control for Suppressing Stick-Slip in Oil Well Drillstrings. IEEE Control Systems Magazine 18(2), 19-30. https://doi.org/10.1109/37.664652

[13] Sarker, M. M., Rideout, D. G., \& Butt, S. D. (2012). Advantages of an LQR Controller for Stick-Slip and Bit Bounce Mitigation in an Oilwell Drillstring. Proceedings of ASME 2012 International Mechanical Engineering Congress \& Exposition, Houston, USA, 1305-1313.

[14] Patil, P. A. \& Teodoriu, C. (2013). A comparative review of modelling and controlling torsional vibrations and experimentation using laboratory setups. Journal of Petroleum Science and Engineering 112, 227-238. https://doi.org/10.1016/j.petrol.2013.11.008

[15] Wu, S., Li. J., \& Liu, L. (2010). Modelling and Compound Control of Disk Brake Automatic Drilling System, Proceedings of $2^{\text {nd }}$ International Conference on Computer Engineering and Technology, Chengdu, China, 45-49.

[16] Ray, J. (2006). Well Drilling Control System, US Patent No. 6994172.

[17] Zhao, Q., Wang, F., Wang, W., \& Deng, H. (2007). Adaptive Fuzzy Control Technology for Automatic Oil Drilling System. Proceedings of 2007 IEEE International
Conference on Automation \& Logistics, Jinan, China, 21232127. https://doi.org/10.1109/ICAL.2007.4338926

[18] Canudas-de-Wit, C., Rubio, F. R., \& Corchero, M. A (2008). D-OSKIL: A New Mechanism for Controlling StickSlip Oscillations in Oil Well Drillstrings. IEEE Transactions on Control Systems Technology, 16(6), 1177-1191. https://doi.org/10.1109/TCST.2008.917873

[19] Naslin, P. (1968). Essentials of Optimal Control, London: Illife Books.

[20] Armstrong-Hélouvry, B., Dupont, P., \& Canudas-de-Wit, C. (1994). A Survey of Models, Analysis Tools and Compensation Methods for the Control of Machines with Friction. Automatica, 30(7), 1083-1138. https://doi.org/10.1016/0005-1098(94)90209-7

[21] Schröder, D. (2007). Elektrische Antriebe - Regelung von Antriebssystemen, Berlin: Springer-Verlag.

[22] Šprljan, P., Pavković, D., Klaić, M., Staroveški, T. \& Cipek, M. (2018). Laboratory Prototyping of Control System Retrofitting Designs for Oil Drilling Applications. Proceedings of $10^{\text {th }}$ International Conference on Management of Technology - Step to Sustainable Production, Primošten, Croatia, 1-11.

\section{Contact information:}

Pavle ŠPRLJAN, mag. ing. el. techn. inf. HELB d.o.o.

Industrijska ulica 1, Božjakovina, 10370 Dugo Selo, Croatia pavle.sprljan@helb.hr

Danijel PAVKoVIĆ, PhD, Associate Professor

(Corresponding author)

University of Zagreb, Faculty of Mechanical Engineering and Naval Architecture Ivana Lučića 5, 10002 Zagreb, Croatia

danijel.pavkovic@fsb.hr

Mihael CIPEK, PhD

University of Zagreb, Faculty of Mechanical Engineering and Naval Architecture Ivana Lučića 5, 10002 Zagreb, Croatia

mihael.cipek@fsb.hr

\section{Miho KLAIĆ, PhD}

University of Zagreb, Faculty of Mechanical Engineering and Naval Architecture Ivana Lučića 5, 10002 Zagreb, Croatia

miho.klaic@fsb.hr

Tomislav STAROVEŠKI, PhD, Assistant Professor

University of Zagreb, Faculty of Mechanical Engineering and Naval Architecture Ivana Lučića 5, 10002 Zagreb, Croatia

tstaroveski@gmail.com

Davor KOLAR, mag. ing. mech.

University of Zagreb, Faculty of Mechanical Engineering and Naval Architecture Ivana Lučića 5, 10002 Zagreb, Croatia

davor.kolar@fsb.hr 